\section{OPEN ACCESS}

Edited by:

Alfredo Addeo,

Geneva University Hospitals

(HUG), Switzerland

Reviewed by:

Raheleh Roudi,

The University of Texas Health Science Center at San Antonio, United States

Giuseppe Giaccone,

Cornell University, United States

*Correspondence:

Beatrice Aramin

beatrice.aramini@unimore.it

tThese authors share first authorship

¥These authors share last authorship

Specialty section: This article was submitted to Thoracic Oncology,

a section of the journal

Frontiers in Oncology

Received: 13 December 2019 Accepted: 09 April 2020 Published: 15 May 2020

Citation:

Masciale V, Grisendi G, Banchelli F, D'Amico R, Maiorana A, Sighinolfi P, Brugioni L, Stefani A, Morandi U, Dominici M and Aramini B (2020) Cancer Stem-Like Cells in a Case of an Inflammatory Myofibroblastic

Tumor of the Lung.

Front. Oncol. 10:673.

doi: $10.3389 /$ fonc. 2020.00673

\title{
Cancer Stem-Like Cells in a Case of an Inflammatory Myofibroblastic Tumor of the Lung
}

\begin{abstract}
Valentina Masciale ${ }^{1 \dagger}$, Giulia Grisendi ${ }^{2 \dagger}$, Federico Banchelli ${ }^{3}$, Roberto D'Amico ${ }^{3}$, Antonino Maiorana ${ }^{4}$, Pamela Sighinolfi ${ }^{4}$, Lucio Brugioni ${ }^{5}$, Alessandro Stefani ${ }^{1}$, Uliano Morandi ${ }^{1}$, Massimo Dominici ${ }^{2 \neq}$ and Beatrice Aramini ${ }^{1 * \neq}$
\end{abstract}

\begin{abstract}
${ }^{1}$ Division of Thoracic Surgery, Department of Medical and Surgical Sciences, University of Modena and Reggio Emilia, Modena, Italy, ${ }^{2}$ Division of Oncology, Department of Medical and Surgical Sciences, University of Modena and Reggio Emilia, Modena, Italy, ${ }^{3}$ Center of Statistic, Department of Medical and Surgical Sciences, University of Modena and Reggio Emilia, Modena, Italy, ${ }^{4}$ Department of Medical and Surgical Sciences, Institute of Pathology, University of Modena and Reggio Emilia, Modena, Italy, ${ }^{5}$ Internal Medicine and Critical Care Unit, Department of Integrated Medicine, Emergency Medicine and Medical Specialties, University of Modena and Reggio Emilia, Modena, Italy
\end{abstract}

Background: Inflammatory myofibroblast tumor (IMT) is a rare tumor with obscure etiopathogenesis in which different inflammatory cells and myofibroblastic spindle cells are seen histologically. Although the majority of these neoplasms have a benign clinical course, the malignant form has also been reported. The gold standard is surgical treatment for complete removal. Our report describes a 50-year-old woman who underwent surgery for IMT of the lung. The aim is to determine whether cancer stem cells may be present in IMT of the lung.

Methods: In April 2018, the patient underwent surgery for tumor mass asportation through lateral thoracotomy. The histology of the tumor was consistent with IMT of the lung. The ALDEFLUOR assay, after tissue digestion, was used to identify and sort human lung cancer cells expressing high and low aldehyde dehydrogenase (ALDH) activity. SOX2, NANOG, OCT-4, and C-MYC positivity were additionally determined by immunohistochemistry.

Results: The specimen contained $1.10 \% \mathrm{ALDH}^{\text {high }}$ cells among all viable lung cancer cells, which indicates the population of cancer stem cells is not negligible. Immunohistochemically assessed cell positivity for ALDH1A1, SOX2, NANOG, OCT-4, and c-MYC, which are considered as lung cancer stem-like cells markers.

Conclusion: For the first time, we demonstrated the presence of cancer stem cells in a case of IMT of the lung. This finding may provide a base for considering new pathological and molecular aspects of this tumor. This perspective suggests further studies to understand the possibility of developing recurrence depending on the presence of cancer stem cells.

Keywords: inflammatory myofibroblastic tumor of the lung, cancer stem cells, cancer stem-like cells, mitosis, target therapy 


\section{INTRODUCTION}

The inflammatory myofibroblastic tumor (IMT), first described by Brunn in 1937, is an extremely rare type of inflammatory pseudo-tumor. The prevalence is between 0.04 and $0.7 \%$, independent of gender and race (1-3). It is debated whether an IMT is a benign or malignant lesion and this is often challenging for further clinical decisions. However, the lungs are considered the most common site for the presentation of this tumor (1).

There are cases of recurrence described in the literature, not only in the lungs but also in other organs, however the recurrence rate at 10 year survival is lower than $90 \%(4,5)$. Beside this aspect, the pathological nature of this tumor is still debated.

In 2002 the World Health Organization classified IMT as an intermediate grade malignancy (6). One of the most recent discoveries is related to chromosomal translocation involving the ALK gene, which seems to be present in $50 \%$ of cases with malignant characteristics (7). The treatment of choice for IMTs is surgical resection in order to guarantee a favorable prognosis (4).

Our work aims to detect the presence of cancer stem-like cells (CSCs) in a case of IMT of the lung by immunohistochemical testing for the most common CSCs markers, with aldehyde dehydrogenase (ALDH), as well as for the presence of pluripotent transcription factors such as OCT4, SOX-2, NANOG, and CMYC, which modulate biological CSC activities (8-10). This will provide a base for further studies with a larger cohort of patients considering the presence of CSCs as a new pathological marker and a possible predictive factor of aggressiveness in this type of tumor.

\section{METHODS}

\section{Case Presentation}

In April 2018, a 47-year-old woman came to our attention for dyspnea and tachycardia under exertion. An x-ray of the chest showed a large mass in the left hemithorax. A CT scan with enhancement presented a $40 \times 30 \mathrm{~cm}$ mass involving the left upper lobe of the lung. A CT guided biopsy gave a diagnosis of benign lung tumor. An Emission Tomography - Computed Tomography (PET/CT) scan showed a very mild uptake at the level of the nodule (SUV $\max =2.3$ ) with no other signs of uptake in other parts of the body (Figure 1).

For the symptomatology and the dimension of the mass, the patient underwent a left upper lobectomy through lateral thoracotomy. The final histology showed an IMT of the lung. The cells were positive for actin in smooth muscle, although negative for ALK, MNF116, and estrogenic receptors, as well as for tuberculosis.

Patient underwent a clinical check ten days after surgery by the oncologist who suggested a period of follow up every 6 months for the first and second year from surgery, and every year after the second year, for a total of 5 years of radiological and clinical monitoring.

Abbreviations: ALDH, aldehyde dehydrogenase; FACS, fluorescence-activated cell sorting; CSCs, cancer stem cells; SSC, side scatter; FSC, forward scattered; IMT, inflammatory myofibroblastic tumor.

\section{Cells Extraction and FACS Analysis}

Sterile Dulbecco's PBS (L1825-BC-Merck Millipore) was used to wash the IMT tissue, then minced mechanically into millimetric pieces, and further digested using MACS $^{\mathrm{TM}}$ CTube (Miltenyi) tumor dissociation kit, according to the manufacturer's instructions. The tissue was digested for $60 \mathrm{~min}$ at $37^{\circ} \mathrm{C}$, filtered through a sterile cell strainer and centrifuged at $300 \times \mathrm{g}$ for $5 \mathrm{~min}$, then resuspended in a DMEM and HAM'S F12 media mixture (2:1) (Gibco) containing penicillin-streptomycin and glutamine. The primary single-cell suspension was diluted in an ALDEFLUOR buffer containing BODIPY-aminoacetaldehyde (STEMCELL Technologies, Vancouver, BC). The morphology of the cell population was studied using side scatter (SSC) and forward scatter (FSC). Dead cells were identified and eliminated using 7-AAD (7-amino-actinomycin D) staining. Cell sorting and ALDH analysis were performed using a FACS-ARIA III (Becton Dickinson, Franklin Lakes, NJ). Results were analyzed by fluorescence-activated cell sorting (FACS) Diva software (Becton Dickinson). ALDH ${ }^{\text {high }}$ gate was included as gating strategy (11-13).

\section{Immunohistochemistry}

The patient's slides were deparaffinized, rehydrated and then washed in PBS. Sodium citrate buffer was used for antigen retrieval. Samples were incubated with anti- ALDH1A1 (1:100) (Abcam, Cambridge, UK), anti-SOX2 (1:200) (MA1-014 Thermo Fisher Scientific, Meridian Road Rockford, IL, USA), anti-NANOG (1:200) (Thermo Fisher Scientific, Meridian Road Rockford, IL, USA), anti-OCT-4 (Cell Marque, Sierra College Blvd. Rocklin, California United States and anti-cMYC (Ventana Medical Systems, Tucson, Arizona, USA) overnight at $4{ }^{\circ} \mathrm{C}$. Images were collected and the positivity was evaluated with Zeiss AxioCam ICc 3 High-Resolution through an Axioskop microscope camera. Section samples were investigated to evaluate the immunoreactivity to the markers used. A semi-quantitative method based on the evaluation of the positivity of the tumor cells was used. Here are shown the score classes: 0 ( $<5 \%$ positive), 1 ( 5 to $25 \%$ positive), 2 ( $>25$ to $50 \%$ positive), 3 ( $>50$ to $75 \%$ positive), and 4 ( $>75 \%$ positive) (14). Sections were scored by two trained investigators, blinded to patient's outcome and other clinical findings.

\section{RESULTS}

\section{Clinical Setting}

The patient was discharged after six days from surgery with no complications. A chest $\mathrm{x}$-ray after one week was normal following the operation. The patient underwent follow up and no recurrence was observed within a year after surgery.

\section{ALDH ${ }^{\text {high }}$ Stem Cells Were Identified in Primary Cells of an IMT of the Lung}

Tumor tissue dissociation efficiently released cancer cells characterized by a heterogeneous morphology, as illustrated in the widespread FSC and SSC values (Figure 2) (1113). The mean viability of the samples was $99.7 \%$ based 


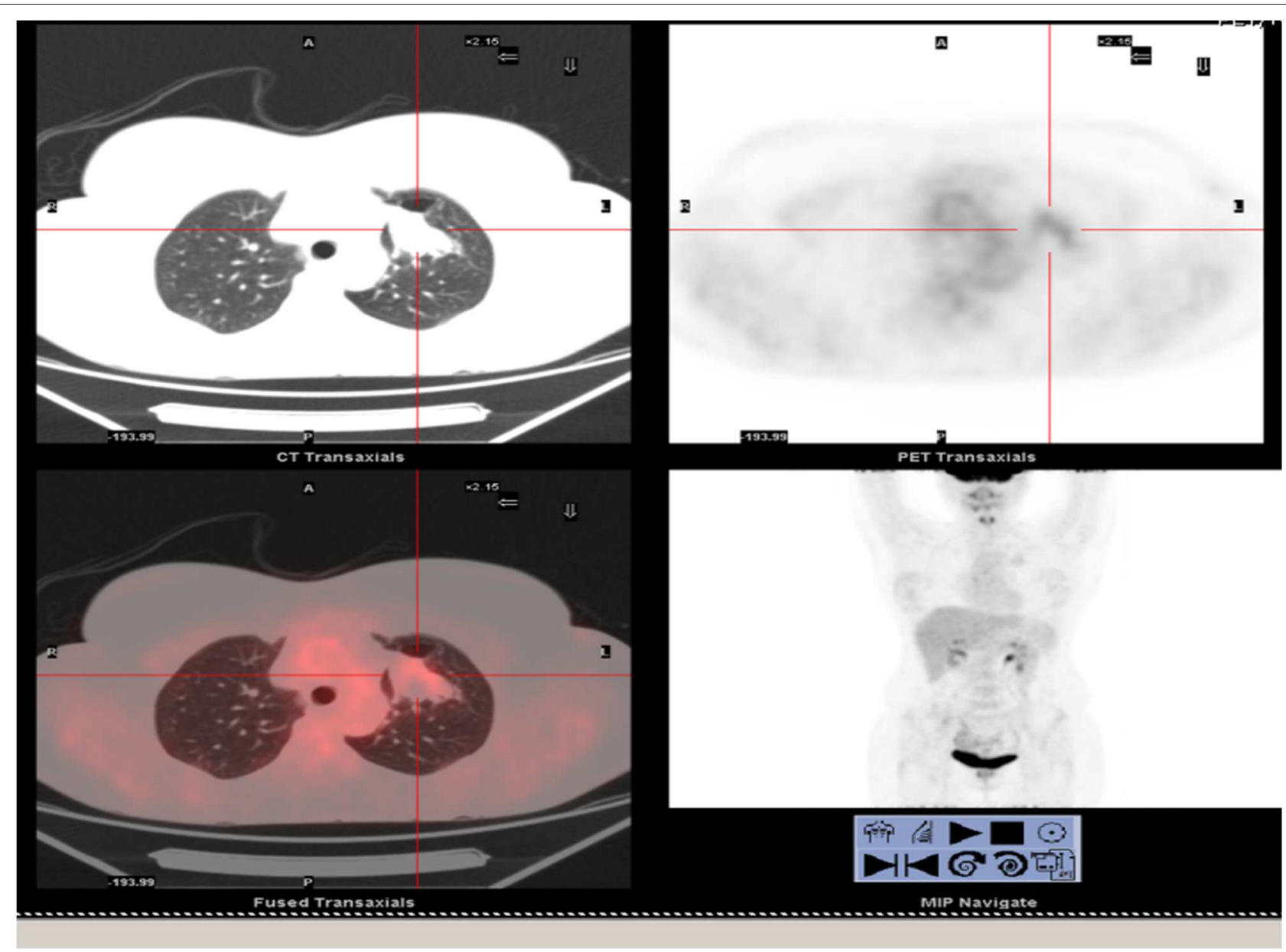

FIGURE 1 | Total body PET/CT scan. Lung nodule at the upper left lobe showed a very low uptake of the lesion.

on 7-AAD staining. These data further confirmed that the developed dissociation procedure was a non-toxic approach to isolating cells from tumor tissues. The CSCs were physically separated from the bulk parental tumor cells and recovered by FACS according to the following gating strategy. Tumor cells were first identified based on their morphological parameters (FSC/SSC), and the ALDH activity was measured in the 7-AAD negative cell population only (Figure 2). $\mathrm{ALDH}^{\text {low }}$ and $\mathrm{ALDH}^{\text {high }}$ cells were both selected and sorted (Figure 2). An ALDH ${ }^{\text {high }}$ subpopulation accounted for $1.10 \%$ of all viable lung cancer cells, which indicates that a non-negligible population of tumor cells had characteristics of CSCs.

\section{Immunohistochemical Evaluation of the ALDH1A1, SOX2, NANOG, OCT-4, and c-MYC Stem Cell Markers in an IMT of the Lung}

To further evaluate the stemness of the cells extracted from the tumor biopsy, SOX2 immunohistochemistry was performed. Positive cells from tissue slides, represented by brown nuclei, were analyzed at $10 \mathrm{x}$ and $20 \mathrm{x}$ magnification. As expected from the FACS analysis, a non-negligible percentage of the cells were positive for ALDH1A1, SOX2, NANOG, OCT-4, and c-MYC (Figure 3).

\section{DISCUSSION}

In our report we first described the presence of cancer stemlike cells in a case of IMT of the lung. The connection between benign and malignant lesions has been investigated for a long time (15-17). Besides the different causes of malignancy, infectious disease may be one of the main causes of induced tumorigenesis (18). In fact the inflammatory microenvironment seems to be the key for the development and maintenance of the CSCs' niche (19). These mechanisms can be justified through the enhancement of proliferation, induction and metastatic signaling (15). In this report, our aim is to highlight the presence of cancer stem-like cells in combination with IMT inflammatory components. In particular, the possibility of emerging inflammatory mechanisms inducing stemness of CSCs has been previously described (19). In breast cancer, 

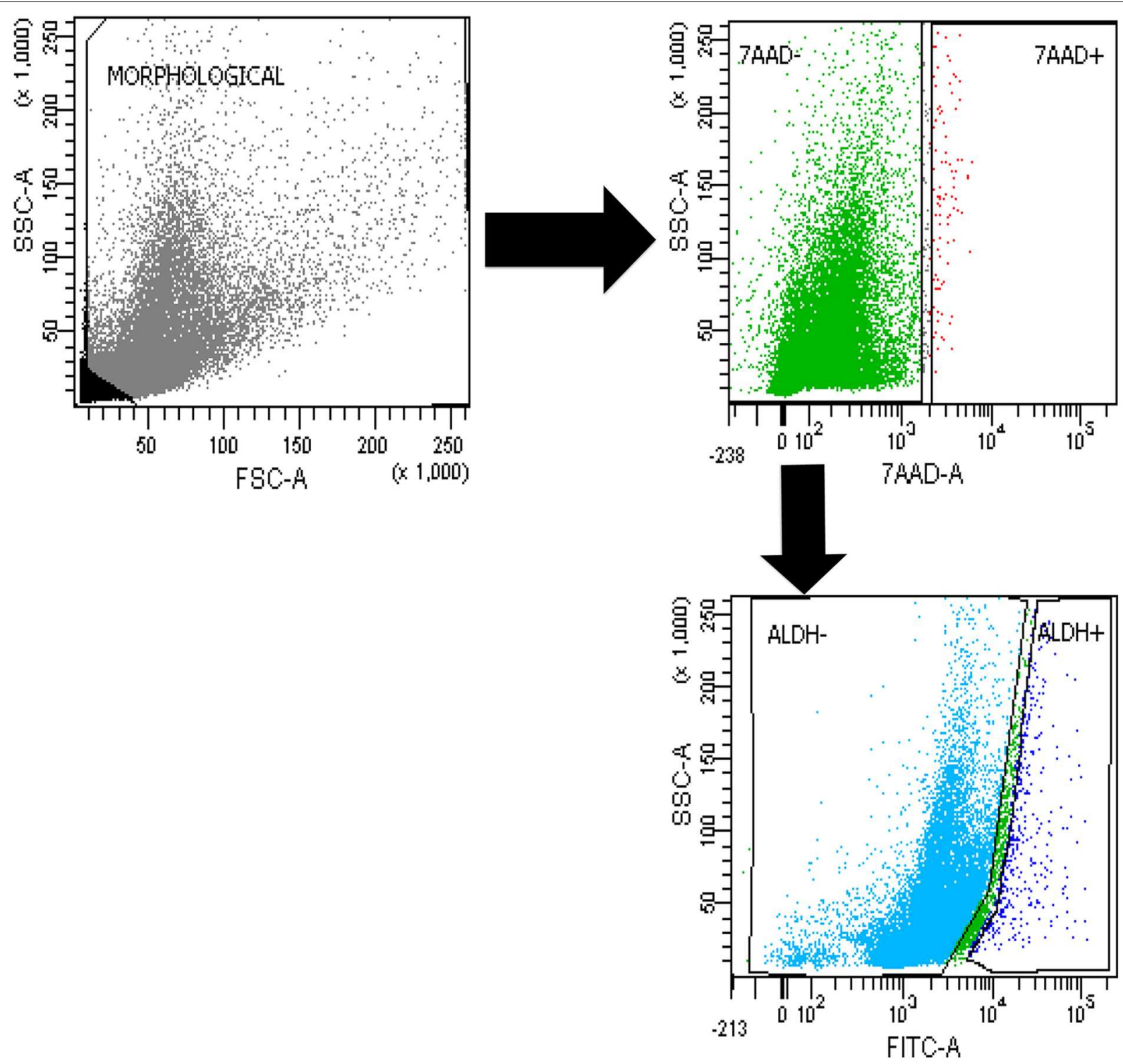

FIGURE 2 | FACS analysis. Cytofluorimetric analysis of ALDH high cells in a case of lung myofibroblastic tumor.

for example, the inflammatory factors are considered as one of the main causes of tumorigenesis $(20,21)$. However, the histogenesis of IMTs is unclear at the moment; some researchers suggest that IMTs are benign lesions with impacts for surgery, trauma, radiotherapy, steroids, and infectious agents, without convincing explanations for the entire scientific community (22-24). There are other hypothesis suggesting that IMTs are tumors related to genetic modifications, such as the recurrent involvement of chromosomal region $2 \mathrm{p} 23$, which seems to induce the aggressive local behavior and metastasis of this tumor (25). In particular, Coffin et al. demonstrated that some IMTs are neoplastic lesions with clonal aberrations (25). Additionally, it is very difficult to define histologically specific characteristics for this disease which can be used to define possible markers, and this is probably due to the impossibility of distinguishing heterogeneity in clinical aspects (26).

As a result, several teams tried to define lesions as falling under the category of IMT.

The World Health Organization has classified IMTs as a distinct entity, being tumors of intermediate biological potential for their capacity to generate local recurrence and, in some cases, distant metastasis (27).

Histologically IMTs are described as cellular or fascicular fibroblastic proliferations associated with chronic inflammatory infiltrate (27). It has been suggested that there are histologic criteria to define the malignant transformation as, for example, round cells associated with necrosis, large nucleoli, several 

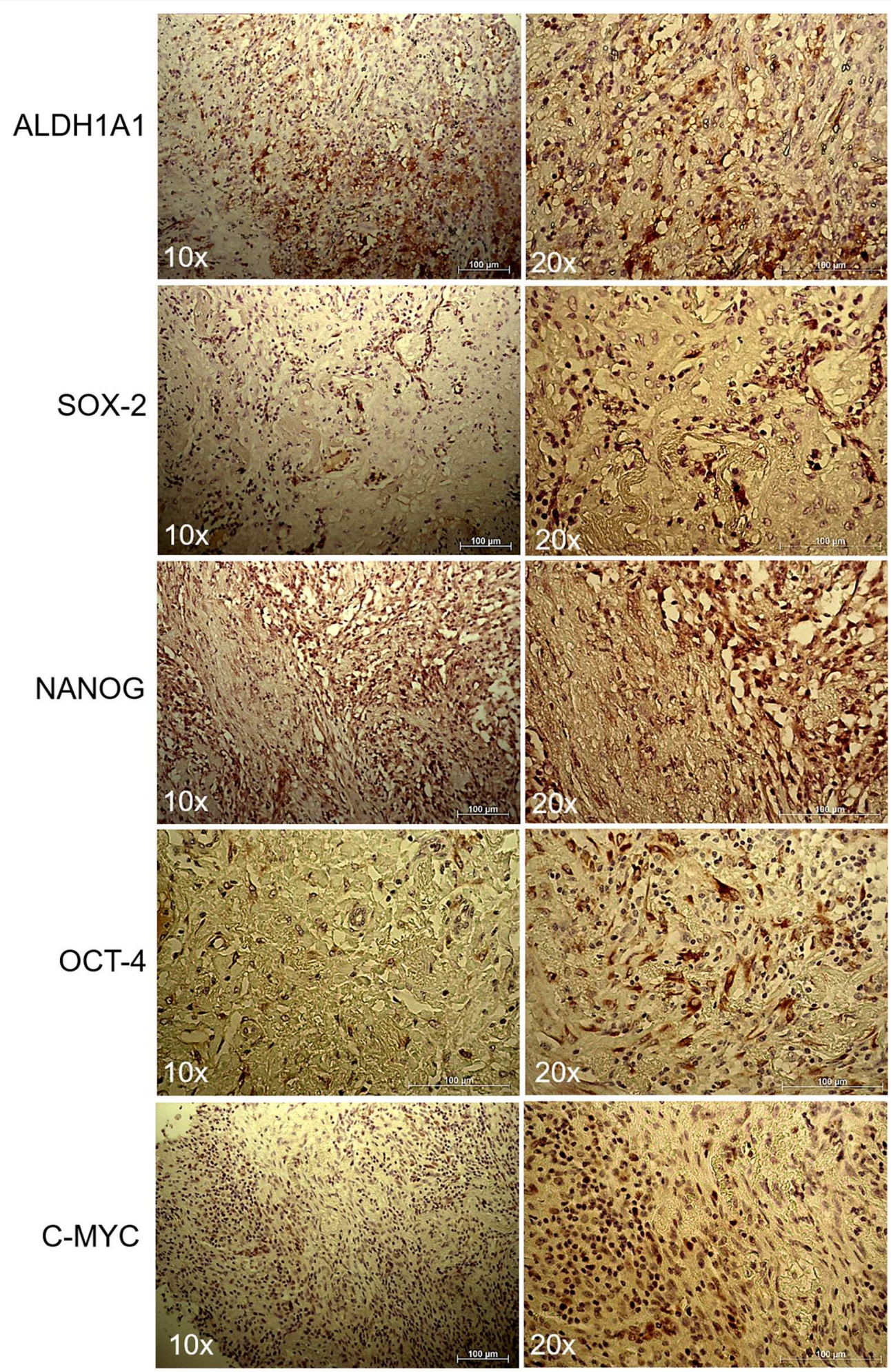

FIGURE 3 | Immunohistochemistry of lung myofibroblastic tumor. Representative immunohistochemical staining of ALDH1A1, SOX2, NANOG, OCT-4, and c-MYC stem cell markers on a myofibroblastic tumor. Images were shown at 10x and 20x magnification.

mitoses, etc. (27). However, the main characteristic of these tumors is the myofibroblast, which justified the term of "inflammatory myofibroblastic tumors" (26). However, no attention until now has been given to the possible presence of cancer stem-cells in this tumor (27-30). Our study represents the first attempt at highlighting new cell populations that may be the 
key to better characterizing this type of tumor. In conclusion, we aim to determine new pathological markers as well as to aid the development of targeted therapies.

\section{DATA AVAILABILITY STATEMENT}

The datasets generated for this study are available on request to the corresponding author.

\section{ETHICS STATEMENT}

The studies involving human participants were reviewed and approved by the Ethics Committee at University Hospital of Modena, MODENA, Italy, on 17 March 2017, Prot. N. 914/C.E and has been performed in accordance with the Declaration of Helsinki. The patients/participants provided their written informed consent to participate in this study.

\section{AUTHOR CONTRIBUTIONS}

The idea for the manuscript was conceived in September 2016 by $\mathrm{BA}$ and $\mathrm{MD}$ and was further developed by $\mathrm{VM}, \mathrm{GG}, \mathrm{FB}, \mathrm{RD}$ 'A, AM, LB, AS. AM and PS were involved in histopathological diagnosis. BA, VM, and FB wrote the first draft of the manuscript.

\section{REFERENCES}

1. Elmadi A, Rami M, Khattala K, Chater L, Harmouch T, Atmani S, et al. Pseudotumeur inflammatoire pulmonaire chez un enfant. J Pediatr Puericulture. (2011) 24:69-71. doi: 10.1016/j.jpp.2011.02.004

2. Pinilla I, Herrero Y, Torres MI, Nistal M, Pardo M. Tumor inflamatorio miofibroblástico pulmonar. Radiología. (2007) 49:53-5. doi: 10.1016/S0033-8338(07)73718-9

3. Matsubara O, Mark EJ, Ritter JH. Pseudoneoplastic lesions of the lungs, pleural surfaces, and mediastinum. In: Wick MR, Humphrey PA, Ritter JH, editors. Pathology of Pseudoneoplastic Lesions. New York, NY: LippincottRaven. (1997). p. 100-9.

4. Moon HC, Yoon JH, Wook Kang G, Lee SH, Baek JS, Kim SY, et al. A case of recurrent pulmonary inflammatory myofibroblastic tumor with aggressive metastasis after complete resection. TubercRespir Dis (Seoul). (2013) 75:1659. doi: 10.4046/trd.2013.75.4.165

5. Doroudinia A, Kaghazchi F, Mehrian P, Dorudinia A. Recurrent inflammatory myofibroblastic tumour of the lung: FDG PET/CT scan findings. BMJ Case Rep. (2018) 2018. pii: bcr-2018-224373. doi: 10.1136/bcr-2018224373

6. Coffin CM, Fletcher JA. Inflammatory myofibroblastic tumour. In: Fletcher CD, Unni KK, Mertens F. editors. World Health Organization of Classification of Tumors: Pathology and Genetics of Tumors of Soft Tissue and Bone. Lyon: IARC Press (2002). p. 91-3.

7. Minoo P, Wang HY. ALK-immunoreactive neoplasms. Int J Clin Exp Pathol. (2012) 5:397-410.

8. Yang L, Shi P, Zhao G, Xu J, Peng W, Zhan J, et al. Targeting cancer stem cell pathways for cancer therapy. Signal Trans Target Ther. (2020) 5:8. doi: 10.1038/s41392-020-0110-5

9. Sedaghat S, Gheytanchi E, Asgari M, Roudi R, Keymoosi H, Madjd Z. Expression of cancer stem cell markers OCT4 and CD133 in transitional cell carcinomas. Appl Immunohistochem Mol Morphol. (2017) 25:196202. doi: 10.1097/PAI.0000000000000291

10. Kalantari E, Saadi FH, Asgari M, Shariftabrizi A, Roudi R, Madjd Z. Increased expression of ALDH1A1 in prostate cancer is correlated with tumor aggressiveness: a tissue microarray study
$\mathrm{BA}$ and UM have been involved in surgery and tissue collection. VM and GG performed laboratory experiments, whereas FB and RD'A performed the statistical analysis. BA, VM, FB, MD, RD'A, AM, and UM reviewed and edited the manuscript before submission. All authors approved the final manuscript before the submission.

\section{FUNDING}

The Project has been supported by funds from the Division of Thoracic Surgery of the University Hospital of Modena and from the Laboratory of Cellular Therapy of the University of Modena and Reggio Emilia, from an unrestricted grant from Myriad Inc. (US) and from the Italian Ministry of Education, University and Research: Departments of Excellence 2017. The funders had no role in the study design, data collection and analysis, decision to publish, or preparation of the manuscript.

\section{ACKNOWLEDGMENTS}

The Project has been supported by the funds from unrestricted grant from Myriad Inc. (US) and from the Italian Ministry of Education, University and Research: Departments of Excellence 2017. of iranian patients. Appl Immunohistochem Mol Morphol. (2017) 25:592-8. doi: 10.1097/PAI.0000000000000343

11. Masciale V, Grisendi G, Banchelli F, D’Amico R, Maiorana A, Sighinolfi P, et al. Isolation and identification of cancer stem-like cells in adenocarcinoma and squamous cell carcinoma of the lung: a pilot study. Front Oncol. (2019) 9:1394. doi: 10.3389/fonc.2019.01394

12. Masciale V, Grisendi G, Banchelli F, D’Amico R, Maiorana A, Sighinolfi P, et al. Correlating tumor-infiltrating lymphocytes and lung cancer stem cells: a cross-sectional study. Ann Transl Med. (2019) 7:619. doi: 10.21037/atm.2019.11.27

13. Masciale V, Grisendi G, Banchelli F, D'Amico R, Maiorana A, Morandi U, et al. Cancer stem-neuroendocrine cells in an atypical carcinoid case report. Transl Lung Cancer Res. (2019) 8:1157-62. doi: 10.21037/tlcr.2019.12.07

14. Kahlert C, Bergmann F, Beck J. Low expression of aldehyde deyhdrogenase 1A1 (ALDH1A1) is a prognostic marker for poor survival in pancreatic cancer. BMC Cancer. (2011) 11:275. doi: 10.1186/1471-2407-11-275

15. Balkwill F, Mantovani A. Inflammation and cancer: Back to Virchow? Lancet. (2001) 357:539-45. doi: 10.1016/S0140-6736(00)04046-0

16. Arias JI, Aller MA, Arias J. Cancer cell: using inflammation to invade the host. Mol Cancer. (2007) 6:29. doi: 10.1186/1476-4598-6-29

17. Morgillo F, Dallio M, Della Corte CM, Gerarda Gravina A, Viscardi G, Loguercio $\mathrm{C}$, et al. Carcinogenesis as a result of multiple inflammatory and oxidative hits: a comprehensive review from tumor microenvironment to gut microbiota. Neoplasia. (2018) 20:721-33. doi: 10.1016/j.neo.2018.05.002

18. Zhang S, Yang $\mathrm{X}$, Wang L, Zhang C. Interplay between inflammatory tumor microenvironment and cancer stem cells. Oncol Lett. (2018) 16:67986. doi: 10.3892/ol.2018.8716

19. Jeong YJ, Hoon KO, Sung HP, Jin GB. Association between inflammation and cancer stem cell phenotype in breast cancer. Oncol Lett. (2018) 15:2380-6. doi: 10.3892/ol.2017.7607

20. Biselli R, Boldrini R, Ferlini C, Boglino C, Inserra A, Bosman C. Myofibroblastic tumours: neoplasias with divergent behaviour. Ultrastructural and flow cytometric analysis. Pathol Res Prac. (1999) 195:619-32. doi: 10.1016/S0344-0338(99)80127-7

21. Coffin CM, Dehner LP, Meis-Kindblom JM. Inflammatory myofibroblastic tumor, inflammatory fibrosarcoma, and related lesions: an historical review 
with differential diagnostic considerations. Sem Diagn Pathol. (1998) 1 5:102-10.

22. Takeda SI, Onishi Y, Kawamura T, Maeda H. Clinical spectrum of pulmonary inflammatory myofibroblastic tumor. Interact Cardiovasc Thor Surg. (2008) 7:629-33. doi: 10.1510/icvts.2007. 173476

23. Coffin CM, Patel A, Perkins S, Elenitoba-Johnson KS, Perlman E, Griffin CA. ALK1 and p80 expression and chromosomal rearrangements involving 2p23 in inflammatory myofibroblastic tumor. Modern Pathology. (2001) 14:56976. doi: $10.1038 /$ modpathol.3880352

24. Gleason BC, Hornick JL. Inflammatory myofibroblastic tumours: Where are we now? J Clin Pathol. (2008) 61:428-37. doi: 10.1136/jcp.2007. 049387

25. Fletcher CDM. Diagnostic histopathology of tumors. In: Fletcher CDM, editor. Soft Tissue Tumors. Philadelphia, PA: Churchill Livingstone (2007). p. 1553-4.

26. Kosma L, Khaldi L, Galani P, Mytas D, Lafoyianni S. A rare case of an inflammatory myofibroblastic tumor in a middle-aged female. Case Rep Oncol Med. (2012) 2012:148053. doi: 10.1155/2012/ 148053

27. Turdo A, Veschi V, Gaggianesi M, Chinnici A, Bianca P, Todaro M, et al. Meeting the challenge of targeting cancer stem cells. Front Cell Dev Biol. (2019) 7:16. doi: 10.3389/fcell.2019.00016
28. Zhao Y, Dong Q, Li J, Zhang K, Qin J, Zhao J, et al. Targeting cancer stem cells and their niche: perspectives for future therapeutic targets and strategies. Semin Cancer Biol. (2018) 53:139-55. doi: 10.1016/j.semcancer.2018.08.002

29. Sullivan JP, Spinola M, Dodge M, Raso MG, Behrens C, Gao B, et al. Aldehyde dehydrogenase activity selects for lung adenocarcinoma stem cells dependent on Notch signalling. Cancer Res. (2010) 70:993748. doi: 10.1158/0008-5472.CAN-10-0881

30. Prabavathy D, Swarnalatha Y, Ramadoss N. Lung cancer stem cells-origin, characteristics and therapy. Stem Cell Investig. (2018) 5:6. doi: $10.21037 /$ sci.2018.02.01

Conflict of Interest: The authors declare that the research was conducted in the absence of any commercial or financial relationships that could be construed as a potential conflict of interest.

Copyright (c) 2020 Masciale, Grisendi, Banchelli, D’Amico, Maiorana, Sighinolfi, Brugioni, Stefani, Morandi, Dominici and Aramini. This is an open-access article distributed under the terms of the Creative Commons Attribution License (CC BY).

The use, distribution or reproduction in other forums is permitted, provided the original author(s) and the copyright owner(s) are credited and that the original publication in this journal is cited, in accordance with accepted academic practice. No use, distribution or reproduction is permitted which does not comply with these terms. 